\title{
Product Configuration Management in ICT Companies: The Practitioners' Perspective
}

\author{
Hanna Kropsu-Vehkapera ${ }^{1}$, Harri Haapasalo ${ }^{1}$, Olli Jaaskelainen ${ }^{1}$, Kongkiti Phusavat ${ }^{2}$ \\ ${ }^{1}$ Department of Industrial Engineering and Management, University of Oulu, Oulu, Finland \\ ${ }^{2}$ Department of Industrial Engineering, Faculty of Engineering Kasetsart University, Bangkok, Thailand \\ E-mail: \{hanna.kropsu-vehkapera, harri.haapasalo,olli.jaaskelainen\}@oulu.fi, fengkkp@ku.ac.th \\ Received August 30, 2011; revised September 30, 2011; accepted October 20, 2011
}

\begin{abstract}
This article studies practical challenges experienced by ICT (Information and Communication Technology) companies when managing product configuration under the circumstances of various customer requirements, different product portfolios, and extensive product complexity. The analysis from interview results concentrates on the prioritised issues and how to ensure effective product configuration from practitioners' perspective. The results of this study indicate that typical challenges for product configuration formalisation include fuzzy product offering, lack of configuration strategy, mechanisms, and general product structure. This research highlights the need for industrial managers to adapt a top-down approach starting from business and strategy, instead of focusing on the challenges of single products when formalising product configuration. Companies need systematic configuration logic over their entire product portfolio and not to focus only single product variant options. Consequently, they need to define a generic product structure to support product configurations that covers all product types such as hardware, software and services. This study also highlights the need for better formalization of service products since they have become an integral part of ICT products. These findings are derived from actual business circumstances and their current difficulties.
\end{abstract}

Keywords: Configurable Product, Product Configuration, Product Structure, Product Data Management

\section{Introduction}

Companies are facing pressures to continuously supply new innovative products with increasing speed to market. Responding to specific customer requirements through product differentiation is a valid means to succeed in global competition [e.g. 1,2]. New business models include addressing requirements for customisation by introducing new functionalities into existing products $[3,4]$. In addition, customer specific solutions ${ }^{1}$ are introduced, and even traditional manufacturing companies are having to include services as a part of their product offering [e.g. $5,6]$. In order to minimise product costs, companies utilise mass customisation to satisfy diversified customer requirements as producing a unique product for each customer is not viable [e.g. 7-9].

${ }^{1}$ On this article, the term product constituting of a physical product, software, service, but also related documentation. A product that is a combination of some or all of these can also be called a solution [e.g. 5], which is a rather commonly used term in business today and are without exception configured against customer requirements.
Product configuration is widely seen as a quick response to customisation needs while simultaneously keeping costs down $[10,11]$. Product configuration can be understood as a means to react to customer requirements through compiling a fixed set of pre-defined components that are defined on product design phase. This is by giving the customer an opportunity to customise the product within the given set of components, rules and constraints without designing any new components during the order-delivery process. [2,4,12,13].

Product configurations are challenging to deploy and manage in practice due to the vast number of products and product variants as well increased complexity of single products [e.g. 2,14,15]. Particular challenges faced in ICT (Information and Communication Technology) business include product complexity being increased due the products containing a combination of mechanics, electronics, software and lately even services. This is added with rapid technological developments and requirements to generate new products rapidly [12].

Even though customisation through configuration is 
not a new method, the effective management of product configurations is still seen as a challenge. Too often, product configurations are handled on individual product basis, instead of e.g. product families, making the related product data challenging to manage [3]. Systematising product configurations and their management is seen to provide a great potential for improving product development and operational efficiency $[2,10,16]$. Especially in ICT sector, where products are mixture of mechanics, electronics, software, and services requires more uniform way to handle different product types to attain efficiency on product management. One critical way to create the required systematic is discussed e.g. by Helo [17] that configuration variety management requires consistent configuration process that lies on product modelling which is integrated throughout organisational functions.

In order to develop the efficient product configuration management is often discussed as a data system challenge. Typically, digital data systems have a central role in managing product configurations due to the immense amount of required information [18]. As a result of customisation, the amount of product related information is greater than ever, further complicating product management and support [19]. Controlling this product information is an important challenge for modern companies [20-22]. Consequently, in earlier studies configuration management is linked to be part of product data management system where it is mainly handled as a tool that supports the configuration process itself [19,23]. However, data systems are not enough to alone solve the product configuration related management challenge that has expanded due the diversity of products. The experiences show that satisfaction for this supporting data system is not good due the challenges to model the configurable product [e.g. 24]. For example, Hvam, Mortensen and Riis [10] and Forza and Salvador [2] have noted that product configurations must be formalised in order to effectively manage product configurations. This formalisation, however, has turned to be challenging especially when discussing product configuration to be a mixture of different product types (hardware, software, services) and example of this kind of product formalisation are not widely discussed. This article discusses these challenges connected product configuration formalisation where the products are mixtures of different types of product.

This article aims to study what are the practical challenges on product formalisation in the specific industry sector. This article analyses challenges experienced by ICT companies relating to practical realisation of product configurations and formalisation of those. The matter is studied from a managerial perspective, rather than from a technical design perspective and discussed how this challenge could be approached. The article aims to an- swer the following research questions:

RQ1: What are the challenges facing ICT companies when attempting to formalise product configuration?

RQ2: How could industrial managers effectively plan and manage product configurations?

This research is qualitative in nature and the research questions are answered through industrial interviews. Literature review, section 2, is covering the key concept of this study related to product configuration and configuration management. Studying the literature provides the basis for further empirical analyses that follows the literature review (sections 3 and 4). Section 5 discussed the results and its implications. Section 6 concludes the research.

\section{Literature Review}

The literature briefly discusses the key issues relevant for considering product configurations and their management. The effective product configuration requires a big picture approach instead of planning the details of a single products configuration. A company's overall product portfolio and how it comprises of modules, parts, and rules should be represented in a standardised manner throughout the company. A general product representation, what is often described with a product structure, is seen as an important solution for supporting configuration management. The product configuration that is composed is highly information intensive.

\subsection{Literature on Configurable Product}

Product configuration is seen as an answer to meet the needs of individual customers cost effectively [3,4,9,17]. Configurability supports especially the emerging requests to utilise the economy of large-scale component, data, and process reuse. This is to accommodate and increase the product variety $[3,25]$. Therefore, configurability is not a property of a specific product but of a product family to support customisable products [26]. A configurable product has defined to be pre-designed set of components and parts to meet the given range of customer requirements and having pre-designed general product structure [27]. Based on configurable product definition the set of product configurations to generate a solution against customer needs [28] but do not include any new product design development. Thus, designing of product configurations should start from generic product offerings [2]. However, in practice, too often product design focuses on a single product instead of product family [25].

Product configuration gives the customer an opportunity to have the final product built according their choice. 
Customer's choice is guided by the given variants and options. A variant is a group of alternatives, out of which only one is selected, while an option is a characteristics that is either selected or left out. [29]. Configurable product definition includes specifying these variants and options [27], and rules and constraints to configure a product [30].

In order to avoid confusion, the difference between a product variant and a product version should be understood. Different variants are satisfying the different set of requirements (e.g. the size of memory in a personal computer) [31]. A number of variants exist in parallel in a configurable product. New product versions are created to improve some part of an original product-often to reduce costs, improve quality or product performance. A new product version replaces the previous older one. [32] Product variants extent the product family while product versions replace previous products [33].

In order to increase product variety cost effectively, products should have common building blocks. In the case of product configurations, common building blocks can mean product platforms, containing common components, modules, and parts to generate derivative products [e.g. 34,35]. Earlier studies [13,36] almost without exception consider product modularity as a necessity for building configurable products. Many studies focus on organising the technical realisation of modularisation [e.g. 37-39]. It has to be noticed that modularity is not the only way to realise product configuration. The other, less discussed way of realising product families to support customisation is a way where different variation based on parametric components $[2,27,40]$.

Modularity, however, covers also various viewpoints such as diverse process or organisational designs that has been studied fairly extensively from each specific viewpoints [e.g. 41-43]. Consequently, product modularity has strong impact to the diverse operational processes such as organising manufacturing, supply chain, or product sell [44-47]. Thus, when planning the product configuration, also the effects on operational processes and their organisation should be observed [28]. However, a very little is know how to coordinate the product design and product realisation process design $[30,38]$.

Finally, configuration management represents an approach in examining and verifying functional and physical characteristics of a component, a part, and an entire product [48]. This management approach is critical as a company needs to establish the baselines in which a product needs to perform in order to meet customer requirements throughout its life cycles (i.e., use, maintenance, and upgrade). In addition, configuration management seeks to integrate various products that have been designed and are being designed so that the database can be synchronized [49].

\subsection{Literature on Product Structure}

The foundation of product configuration lies in the utilisation of common components, data, and processes. In order to reach this target, configurable products should be represented in a formalised manner. This requires creating a clear representation of company's overall product range, including the utilisation of modules, common parts, and rules that apply to customisation [10]. Standardised understanding over a product is expected to support business processes as well as to specify products, i.e. product configurations. Previous experiences, however, show that companies are lacking in their ability to create a sufficient standardised representations over product offering that would truly support the execution of business processes [10,50].

In order to support configurability, and managing configurations, a single general way to describe company's entire product family and related variations is needed. In the case of product configuration, this presentation must define how the product configuration is actually composed [2]. However, in the case of complex products, the solution base can contain several thousands or even million combinations, making configuration management challenging. This is why a generic representation is required as it is not efficient to describe all of these configurations with single models or bill-of-materials [51]. To support efficient product variety management, this cannot be solved by developing a single product architecture but requires modelling a general product representation.

Product structure is seen as a typical way to model manufactured products. In practice, product structure is considered as the backbone of the business [52]. Product structure represents the product, information linked to the product, as well as the relationship between product components [12,53]. Cheng and Wang [30] discuss the general product structure to be typical way to describe configurable product and its arrangement of ready defined parts. Product structure is discussed in several studies as a general way to conceptualise product that can be utilised throughout the company to offer diverse views over a product for different functions, such as product development, sales, production or maintenance [e.g. 12,54-56]. Consequently, the product structure, as a product representation, is seen to standardise the understanding over a product between different functions.

Product structure is also utilised in some information systems to conceptualise the product, mainly in configurators and in product data management system $[12,57,58]$. These applications request the information related to a 
product to be structured in appropriate ways including the rules for product composition [e.g. 59,60].

\subsection{Literature on Product Configuration and Data Systems}

Product complexity, extensive product portfolios, and the fact that all information is in digital format requires a tool to aid in managing product configurations. In the case of configurable products, this tool is often called a configurator. Several studies consider a configurator as an essential tool for creating product configurations efficiently $[2,10,17,61]$. The aim of the configurator is to ensure that selected configurations follow set rules, and that the final combination is based on valid variants and options. All operational functions require information about the composition of configurable products; therefore this information should be available in an appropriate format for the relevant stakeholders.

Typically the challenge is not building the actual tool, configurator, but rather a question of how to manage product configurations as a whole [17]. The mechanism for product configurations and managing customisations in practice are more acute issues to solve before building tools. The core of a configurator is an adequate product representation that describes and defines the product and required configuration data $[1,3,59]$. Colace, De Santo, and Napoletano [62] argue that past studies have not well addressed the issue of defining the required predefined rules and constraints for attaining satisfactory product configurations.

\section{Research Process}

Figure 1 illustrates the research process applied in this study. First, a literature review was conducted to obtain an adequate outline to analyse product configuration from a managerial perspective. Second, company representatives and consultants were interviewed to clarify current practices and challenges relating to product configuration at managerial level. The obtained data was then analysed and finally conclusions were made.

The empirical data was collected by interviewing responsible managers and specialists of ICT companies as well as experts with extensive experience consulting companies on product data management. The interviewees were carefully selected based on their broad knowledge on the subject. In ICT companies, the technical product and configuration details were not in focus as this study concentrates on managerial level view. The interviews covered a broad range of company functions, including product management, product data management, manufacturing, sales and logistics. The interview titles include e.g. product development director and manager, head of new product introduction, sales and marketing manager, head of logistics operations, head of product data management, director of data management, product data managers and coordinators, product architecture, director of operations, business unit manager, senior development manager in product structure development, service manager, director after sales, segment manager, product leader, product platform manager, test technology manager. Consulting experts were interviewed to complement company specific findings to provide a more general outlook.

Table 1 summarises the characteristics of the interviewed companies. The study consisted of a total of 42 interviews, providing a solid basis for analysing product configuration in a versatile manner. The aim of the interviews was to bring forward different aspects on the subject and to document the key challenges.

The companies were selected based on configurations being important for their business. The common nominator for the selected companies was them having a strong need to develop their configuration practices. The companies were selected so that they would represent configuration in a versatile manner, and so that their products would be of different type, hardware, software, solutions, and service. Some of the companies are more advanced in managing configurations while others can be considered more novices. However, all the interviewed companies have realised the significance of product configurations.

All the interviews were conducted by three interviewers in Finland, during 2009-2010. The interviews were conducted informally, in a qualitative manner, allowing the interviews to freely explain and clarify the cases and topics as entities. All the interviews were taped and transcribed to enable deeper analysis.

The researchers analysed the studied companies to obtain company specific understanding over the studied issues, after this, common emerging themes were looked for across the companies and interviews. The data was analysed by grouping the general challenges relating to product configuration formalisation under three main themes clearly re-occurring among the analysed data and

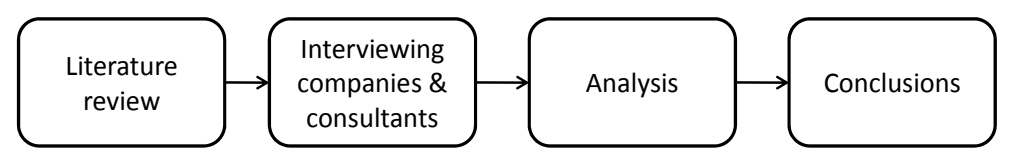

Figure 1. Research process. 
Table 1. Company characteristics.

\begin{tabular}{|c|c|c|}
\hline Company & Key characteristics* & Product \\
\hline A & Large company Operates in Nordic countries & Intangible product; software/Internet based services. \\
\hline B & Large company Operates globally & System products with services (combination of hardware and service). \\
\hline $\mathrm{C}$ & Large company Operates globally & $\begin{array}{l}\text { Embedded system with own software as core. Hardware outsourced but } \\
\text { final solution assembled in-house. }\end{array}$ \\
\hline $\mathrm{D}$ & Medium sized company Operates in Nordic countries & Solutions with own software as core. Also consulting and project services. \\
\hline $\mathrm{E}$ & Large company Operates globally & $\begin{array}{l}\text { System products delivered as projects (including services); embedded } \\
\text { systems with maintenance services. }\end{array}$ \\
\hline $\mathrm{F}$ & Large company Operates globally & Embedded consumer products with update and add-on services. \\
\hline
\end{tabular}

*Company size classified according to EU Commission definition [63].

among all the cases. The topics that were merely company specific configuration challenges are not reported in this study.

\section{Industrial Experience and Results}

The results of this study indicate three typical challenges for product configuration formalisation in studied ICT companies including fuzzy offering, configuration strategy \& mechanisms, and product structure. There is some variation between different companies on how well their product configuration is managed; however, all of them seem to require significant development in their current practices.

\subsection{Fuzzy Offering}

The results of this study indicate that one of the key challenges is fuzzy offering (see Appendix A about authentic interviewee comments on fuzzy offering). In practice, due to customer need variations and product complexity, the number of possible product variations is vast. Sales, product development and production do not necessarily have common understanding over how to manage resulting complex product portfolio. Consequently, customers are being offered products which realisation is unambiguous to internal stakeholders.

According to the interviewees, companies have not clearly decided what is fixed and what can be configured and to what extent. Pre-designed product variants may enable hundreds of thousands different configurations making product data management challenging since the product structure for each variant is, in some cases, managed separately. This leads problems in the point of sales-sales personnel are not able to manage all information on vast product portfolio.

The internal data systems do not support sales making offers, as costs for different product alternatives have not been adequately calculated. Consequently, sales person- nel preparing customer offers are not able to consider what is optimal for the business. Later management of sold items may prove challenging should the product content not be properly defined. Due to inaccurate product content information, after sales services encounter problems relating to software updates, spare parts and such.

Overly wide product portfolio is practically impossible for sales personnel to manage optimally. In addition, testing the functionality of all possible options is not sensible. Consequently testing is conducted when product is delivered. Complex products do not typically work fully when assembled and tested the first time, but modifications are required.

Also the interviewed consultants share the view on total offering. One interviewee phrased this as: "The first thing is to define offered products and understand the composition of a product, and after that it is time to think variants and configurations". A company having a common view of products across the entire organisation is seen as an exception. The most difficult cases are companies with two-level products, where sales item A is also a part of item B. Data systems do support this type of multi-level products; however, problem lies with companies being unable to perceive what the actual sales items are.

\subsection{Configuration Strategy \& Mechanisms}

The second key challenge identified in this study is configuration strategy \& mechanisms. The interviewees highlighted the importance of companies considering product configuration at a higher, more general level, not only product specifically. All the interviewed companies have considered product configuration at least to some degree. Companies have challenges in higher level strategic solutions that could provide more general systematic ways for realising configurations. Companies experience the current situation a mess as numerous con- 
figuration needs are addressed on a case-by-case basis, when more generic design solutions are desired.

Companies have realised that they need to narrow their product portfolios in order to make them more manageable, but they do not know what would be the best mechanisms for this. However, companies do typically not know how to optimise the number of configuration possibilities, as they do not have a configuration strategy. All the interviewees appreciate the potential benefits of controlled configurations, i.e. improved quality of products and services, operation efficiency. It is, nevertheless, unclear to which level in product hierarchy the configurability should be built in.

Some of the interviewed companies have already realised that they need to decide on configuration mechanisms, and parameters one can choose from. Only rare companies have understood that one must have courage to say no, i.e. what alternatives are to be excluded. Configuration parameters have some interdependencies; however, it is not clear for companies how to manage these in an optimal manner. In addition, it is unclear which hierarchy level is the optimal for the company to realise customer's wishes for variation.

The interviewees find it a challenge to combine production and logistics operations, maintenance and technical realisation of product features so that it is beneficial for the company. Very few companies have realised that the key is to differentiate between factors that need to remain flexible, and those that should be maintained constant.

The interviewed companies almost exclusively ignore services and configuration only covers the physical product. This results in service provision not being fully repeatable and consequently the situation is not economically optimal.

The interviewed consultant experts view the lack of configuration strategy has lead to excessive number of configuration alternatives and methods. The consultants would prefer simple solutions that do not have multiple layers. All the interviewed consultants proposed modularisation as a mechanism, even though the literature [e.g. 2] necessarily does not see this as compulsory. A fundamental reason behind configuration challenge is seen to lie in the companies lacking of benchmarking knowledge. Managing configurations is seen as a competitive factor that companies are not willing to share.

\subsection{Product Structure}

The third key challenge identified in this study is product structure. Product structure is seen as a model that unifies and helps in perceiving product configuration. All the studied companies used the concept of product struc- ture for defining products. Product structure is seen by some of the interviewees as a pre-requisite for realising configurations. It seems, however, that there are vast differences among companies on how they utilise the product structure concept for configurations (see Appendix B, Table 1 for company specific details). These differences seem to be due to varying levels of systematic use of configurations, products being different, or history of a company being different. Interviewed consultants view that companies, in general, do not have an understanding over what clear product structure should mean in their specific case.

The practical requirements for developing product structure vary due to differences in the maturity of current practices (see Appendix B, Table 2 for company specific requirements for product structure). Companies that have not defined product structure clearly and have not considered configuration systematically experience compatibility of different products and modules as a challenge. Lack of clear rules for configurations is seen to hinder their realisation in practice. The interviewed consulting experts view that clear mechanisms are required to prevent sales from selling wrong products or product combinations.

Some companies prefer describing products through features and functionalities seen by customers. However, these companies have not found ways to realise this in their data systems.

Creating an optimal product structure is not a simple task. Even if the companies realise that product structure is beneficial for them, their hands are tied due to existing product portfolio and business relationships. Also when considering totally new solutions, it is seen difficult to combine existing practices, such as data systems, with new approaches. One of the interviewed consultants describe one of his customer cases by stating that obtaining an optimal product structure with required modelling and simulation was a laborious project taking 1.5 years. Another expert said that fully implementing a configurable product generation requires approximately 3 years.

\section{Analysis and Discussion}

\subsection{Theoretical Reflections}

Literature represents different level design principles for product configurations [e.g. 29,37,43] and discusses the importance of product structure to formalise product configuration [2,3,59]. Most articles include guidelines to increase common elements at different product levels e.g. product modularisation. The cases analysed in this study showed that ICT companies are struggling with higher-level challenges when formalising their product 
configuration management. The results indicated three important themes in order to develop formalise conception of product configuration and its management including fuzzy offering, general configuration strategies and mechanisms for practical realisation, and creation of product structure that covers different product types. Unfortunately, literature does not provide answers to these challenges when the configurable product is mixture of hardware, software and service. This study provides new knowledge by describing the managerial level realities companies are encountering in ICT sector. This research clearly points out how configuration must be considered at higher level, not only at the level of a single product as typically is the case in industry.

This study is in line with Forza and Salvador [2] by realising that when considering product configurations, one must take into account business aspects, sales, manufacturing, logistics and maintenance. The studied cases show that companies are not following these recommendations, but tend to realise configuration only from technical perspective. This study complements this perspective by highlighting the importance of product data management also for planning realising product configurations. Based on this study, product configuration is an evident area where efficient data management practices can potentially improve business efficiency. As pointed out in theoretical discussion as well as in the empirical part of this study, efficient configuration management requires formalising the products. Unfortunately, the current ways to conceptualise configuration products are not adequate for making relevant configuration rules resulting in the overall offering being fuzzy and configuration management becoming demanding. Also, lacking structure of all product types (hardware, software, service) within general product structure, weaken companies' capability to outline their true product range.

The literature does not provide practical tools for managing product configuration of modern complex ICT products containing hardware, software and services. Earlier studies focus on some parts of those. In order to develop company practices, the product and its configuration should be handled within this wider concept. Business is currently moving towards solution providing [e.g. 5,6] and if companies want profitable handle their products it is not enough just formalise the representation of the mechanical or software part when the real offering includes also service aspects. This study shows how this is an acute challenge for companies. This study provides new information by highlighting that also service viewpoint must be included when product configuration is considered as this seems to be the reality where companies are operating. Currently, very often the service is not defined to be part of configurable products, leading to a situation where they are executed and managed on caseby-case basis. However, this kind of solution is not efficient and made especially their management in data systems to be demanding. The results clearly shows that service aspect should be covered more detailed in academic studies of product configuration. Practitioners also stated the importance to formalise the representation of services in order to better manage those.

\subsection{Managerial Implications}

Managers of ICT companies considering their configuration and product data management ought to follow a top-down approach starting from business and strategy, not from solving the challenges of single products. The results of this study indicate that the more advanced companies strive for this type of approach. Opposed to the more advanced companies, companies that are unable manage their product configurations have started to develop their product configuration systems on a product basis which is not supporting the formalisation of product configuration. The top-down approach is a way to clarify fuzzy offering and make the configuration logic over the entire product portfolio more systematic.

The results of this study indicate that companies should first formulate their general configuration strategy, followed by configuration mechanisms and rules. Currently, too often the starting point is challenges encountered by a single product, resulting in different products being realised via different mechanisms. Overall, it is very important to understand the big picture-how configuration is executed in practise and how the selected mechanisms affect operational processes. This cannot be achieved nor managed from the viewpoint of a single product.

In order to companies to be able to implement their configuration strategy, they need a generic product structure to support unified product configurations. In practice, this will result in solutions being applicable to all products. Also, product designers will be supported by rules preventing product specific solutions. This results in better profitability through avoiding unnecessary hassle. The general product structure is seen to help in formalising the product and how it is understood across the company. The general product structure is seen as a way to minimise the number of new products and related data. General product structure also helps to define all different variants and thus tackle the fuzziness of final offering. However, the requirements for product structure are strongly company specific.

One should not fall under the illusion that selecting and implementing a data system will rectify problems which seem to be the starting point when developing 
product configuration management as stated the experienced consultants. On the contrary, managers need to understand that product structure is required before implementing any data systems. Properly considered product structure improves efficiency and enables integrating different data systems. Product structure needs to cover all different product types so that those can be managed systematically in data systems. In order to efficiently manage the whole, product configuration mechanisms and amount of product data should be minimised.

Managers need to realise that the development process takes some time as it is not wise to jeopardise existing business relationships, current product portfolio or functioning operations. Managers must shift their mentality on product configuration from purely technical thinking towards a business oriented.

\section{Conclusions}

ICT products are complex and there are a vast number of products and product variants as well as different customer segments. As a result, the amount of product related information is greater than ever, further complicating product data management. Unfortunately, data systems are not enough to alone solve the product configuration related management challenge. Product configurations are widely seen as a response to versatile customer requirements. This article analyses challenges experienced by ICT companies relating to practical realisation of product configurations and their formalisation.

The results of this study indicate that one key challenge relating to product configuration formalisation is fuzzy offering. Sales, product development and production do not have adequate common understanding over their product portfolio. As a consequence, customers are often offered products that are difficult to realise. Different approaches for product configuration makes the final product range fuzzy. Another key challenge identified is the lack of configuration strategy \& mechanisms. The results highlight the importance of companies considering product configuration at a higher, more general level, not only product specifically. Advanced companies have realised that they need to narrow their product portfolios in order to make them more manageable. However, companies do typically not know what would be the best mechanisms for this. Companies tend to ignore services when considering product configurations and only acknowledge physical products. Currently the nature of products is changing. Services are becoming integral part of ICT products. The efficient management of the whole product range requires that also other products types are formalised. The third key challenge identified in this study is the incapability of companies to come up with a general product structure that would support product configurations. However, companies see the product structure as a model that potentially unifies and helps in realising product configurations. In addition, lack of clear configuration rules is seen to hinder practical realisation.

When considering product configurations and related data management, industrial managers ought to follow a top-down approach starting from business and strategy, instead of focusing on the challenges of single products. The results of this study show how such a top-down approach is a functional way to clarify fuzzy offering and make configuration logic more systematic over entire product portfolios. Companies need to define a generic product structure to support product configurations. This will further minimise the number of new products and related data. Managers need to understand that product structure is required before implementing any data systems as only selecting and implementing a data system will not alone rectify problems.

The limitations of this study include the number of interviewed companies being limited. Also, the studied companies were versatile in their background, making statistically reliable comparisons challenging. Recommended future study, besides addressing the above described limitations could include deeper analysis over the operational impacts of product configurations. Also, it would be an interesting topic to study how well the findings of this study apply on small companies as they were not covered in this study. In addition, identifying and benchmarking top companies who have successfully built configuration strategies might prove an interesting topic for future study.

\section{Acknowledgements}

The authors would like to thank Dr. Pekka Belt, Dr. Matti Mottonen, and Dr. Janne Harkonen for their support in writing this article.

\section{References}

[1] Y. Huang, H. Liu, W. K. Ng, W. Lu, B. Song and X. Li, "Automating Knowledge Acquisition for Constraint-Based Product Configuration,” Journal of Manufacturing Technology Management, Vol. 19, No. 6, 2008, pp. 744-754. doi:10.1108/17410380810888120

[2] C. Forza and F. Salvador, "Product Information Management for Mass Customization,” Palgrave Macmillan, Houndmills, 2007.

[3] M. Kratochvíl and C. Carson, "Growing Modular: Mass Customization of Complex Products, Services and Software,” Springer, Berlin, 2005.

[4] D. Sabin and R. Weigel, "Product Configuration Frame- 
works-A Survey," IEEE Intelligent Systems and their Applications, Vol. 13, No. 4, 1998, pp. 42-49.

[5] T. S. Baines, H. W. Lightfoot, O. Benedettini and J. M. Kay, "The Servitization of Manufacturing: A Review of Literature and Reflection on Future Challenges,” Journal of Manufacturing Technology Management, Vol. 20, No. 5, 2009, pp. 547-567. doi:10.1108/17410380910960984

[6] H. Gebauer, E. Fleisch and T. Friedli, "Overcoming the Service Paradox in Manufacturing Companies," European Management Journal, Vol. 23, No. 1, 2005, pp.1426. doi:10.1016/j.emj.2004.12.006

[7] S. C. J. Lim, Y. Liu and W. B. Lee, “A Methodology for Building a Semantically Annotated Multi-Faceted Ontology for Product Family Modelling," Advanced Engineering Informatics, Vol. 25, No. 2, 2011, pp. 147-161. doi:10.1016/j.aei.2010.07.005

[8] M. Aldanondo and E. Vareilles, "Configuration for Mass Customization: How to Extend Product Configuration towards Requirements and Process Configuration,” Journal of Intelligent Manufacturing, Vol. 19, No. 5, 2008, pp. 521-535. doi:10.1007/s10845-008-0135-Z

[9] B. J. Pine, "Mass Customization: The New Frontier In Business Competition,” Harvard Business School Press, Boston, 1999.

[10] L. Hvam, N.-H. Mortensen and J. Riis, "Product Customization,” Springer, New York, 2008.

[11] B. Zhu, Z. Wang, H. Yang, R. Mo and Y. Zhao, “Applying Fuzzy Multiple Attributes Decision Making for Product Configuration," Journal of Intelligent Manufacturing, Vol. 19, No. 5, 2008, pp. 591-598. doi:10.1007/s10845-008-0132-2

[12] A. Saaksvuori and A. Immonen, "Product Lifecycle Management,” Springer, Berlin, 2008. doi:10.1007/978-3-540-78172-1

[13] J. Tiihonen, T. Soininen, T. Männistö and R. Sulonen, "Configurable Products-Lessons Learned from the Finnish Industry,” Proceedings of 2nd International Conference on Engineering Design and Automation, Integrated Technology Systems, Goshen, 1998.

[14] B. Anderson, C. Hagen, J. Reifel and E. Settler, "Complexity: Customization's Evil Twin,” Strategy \& Leadership, Vol. 34, No. 5, 2006, pp. 19-27. doi:10.1108/10878570610684801

[15] M. E. McGrath, "Product Strategy for High-Technology Companies: Accelerating your Business to Web Speed,” McGraw-Hill, New York, 2011.

[16] J. Jiao, L. Zhang and K. Prasanna, "Process Variety Modeling for Process Configuration in Mass Customization: An Approach Based," The International Journal of Flexible Manufacturing Systems, Vol. 16, No. 4, 2004, pp. 335-361. doi:10.1007/s10696-005-5171-9

[17] P. T. Helo, "Product Configuration Analysis with Design Structure Matrix,” Industrial Management and Data Systems, Vol. 106, No. 7, 2006, pp. 997-1001. doi:10.1108/02635570610688896

[18] X. Jin, L. Koskela and T. M. King, “Towards an Integrated Enterprise Model: Combining Product Life Cycle
Support with Project Management,” International Journal of Product Lifecycle Management, Vol. 2, No. 1, 2007, pp. 50-63. doi:10.1504/IJPLM.2007.012874

[19] J. Stark, "Product Lifecycle Management: 21st Century Paradigm for Product Realisation,” Springer, New York, 2005.

[20] D. M. Giménez, M. Vegetti, H. P. Leone and G. P. Henning, "Product Ontology: Defining Product-Related Concepts for Logistics Planning Activities,” Computers in Industry, Vol. 59, No. 2-3, 2008, pp. 231-241. doi:10.1016/j.compind.2007.06.019

[21] F. Ameri and D. Dutta, "Product Lifecycle Management: Closing the Knowledge Loops,” Computer-Aided Design \& Applications, Vol. 2, No. 5, 2005, pp. 577-590.

[22] H.-E. Tseng, C.-C. Chang and S.-H. Chang, “Applying Case-Based Reasoning for Product Configuration in Mass Customization Environments," Expert Systems with Applications, Vol. 29, No. 4, 2005, pp. 913-925. doi:10.1016/j.eswa.2005.06.026

[23] R. Kumar and P. S. Midha, “An Intelligent Web-Based Expert System for Analysing a Company’s Strategic PDM Requirement," International Journal of Product Lifecycle Management, Vol. 1, No. 3, 2006, pp. 230-248. doi:10.1504/IJPLM.2006.009404

[24] G. Hong, L. Hu, D. Xue, Y. L. Tu and Y. L. Xiong, "Identification of the Optimal Product Configuration and Parameters Based on Individual Customer Requirements on Performance and Costs in One-of-a-Kind Production," International Journal of Production Research, Vol. 46, No. 12, 2008, pp. 3297-3326.

[25] J. Jiao, T. W. Simpson and Z. Siddique, "Product Family Design and Platform-Based Product Development: A Stateof-the-Art Review,” Journal of Intelligent Manufacturing, Vol. 18, No. 1, 2007, pp. 5-29. doi:10.1007/s10845-007-0003-2

[26] Z. Siddique and J. A. Ninan, "Modeling of Modularity and Scaling for Integration of Customer in Design of Engineer-to-Order Products," Integrated Computer-Aided Engineering, Vol. 13, No. 2, 2006, pp. 133-148.

[27] J. Tiihonen, T. Lehtonen, T. Soininen, A. Pulkkinen, R. Sulonen and A. Riitahuhta, "Modeling Configurable Product Families," 4th WDK Workshop on Product Structuring, Delft, 22-23 October 1998.

[28] E. R. Deciu, E. Ostrosia, M. Ferneya and M. Gheorghe, "Configurable Product Design Using Multiple Fuzzy Models,” Journal of Engineering Design, Vol. 16, No. 2, 2005, pp. 209-235. doi:10.1080/09544820500031526

[29] A. Pulkkinen, "Product Configuration in Projecting Company: The Meeting of Configurable Product Families and Sales-Delivery Process,” Ph.D. Thesis, Tampere University of Technology, Tampere, 2007.

[30] Z. Cheng and L. Wang, "Responsive Consistency Restoration in Interactive Product Configuration by ContentAddressable Memory,” Journal of Intelligent Manufacturing, Vol. 20, No. 4, 2009, pp. 463-479. doi:10.1007/s10845-008-0149-6

[31] A. McKay, F. Erens and M. S. Bloor, "Relating Product 
Definition and Product Variety," Research in Engineering Design, Vol. 2, No. 2, 1996, pp. 63-80. doi:10.1007/BF01607862

[32] B. Westfechtel, B. P. Munch and R. Conradi, “A Layered Architecture for Uniform Version Management," IEEE Transactions on Software Engineering, Vol. 27, No. 12, 2001, pp. 1111-1133. doi:10.1109/32.988710

[33] L. O. Wilson and J. A. Norton, "Optimal Entry Timing for Product Line Extension,” Marketing Science, Vol. 8, No. 1, 1989, pp. 1-17. doi:10.1287/mksc.8.1.1

[34] M. H. Meyer and A. P. Lehnerd, "The Power of Product Platforms: Building Value and Cost Leadership," The Free Press, New York, 1997.

[35] L. T.-S. Lee, "The Effects of Team Reflexivity and Innovativeness on New Product Development Performance,” Industrial Management \& Data Systems, Vol. 108, No. 4, 2008, pp. 548-569.

[36] F. Erens and K. Verhulst, "Architectures for Product Families,” Computers in Industry, Vol. 33, No. 2-3, 1997, pp. 165-178.doi:10.1016/S0166-3615(97)00022-5

[37] T. Kaski, "Product Structure Metrics as an Indicator of Demand-Supply Chain Efficiency: Case Study in the Cellular Network Industry,” Ph.D. Thesis, Helsinki University of Technology, Helsinki, 2002.

[38] F. Salvador, C. Forza and M. Rungtusanatham, "Modularity, Product Variety, Production Volume, and Component Sourcing: Theorizing beyond Generic Prescriptions," Journal of Operations Management, Vol. 20, No. 5, 2002, pp. 549-575. doi:10.1016/S0272-6963(02)00027-X

[39] K. Ulrich and K. Tung, "Fundamentals of Product Modularity," Proceedings of the 1991 ASME Winter Annual Meeting Symposium on Issues in Design/Manufacturing Integration, Atlanta, 1991, pp. 73-45.

[40] X. Luo, Y. Tu, J. Tang and C. K. Kwong, “Optimizing Customer's Selection for Configurable Product in B2C E-Commerce Application," Computers in Industry, Vol. 59, No. 8, 2008, pp. 767-776. doi:10.1016/j.compind.2008.03.003

[41] A. Bask, M. Lipponen, M. Rajahonka and M. Tinnila, "The Concept of Modularity: Diffusion from Manufacturing to Service Production,” Journal of Manufacturing Technology Management, Vol. 21, No. 3, 2009, pp. 355375. doi:10.1108/17410381011024331

[42] M. Howard and B. Squire, "Modularization and the Impact on Supply Relationship," International Journal of Operations and Production Management, Vol. 27, No. 11, 2007, pp. 1192-1212. doi:10.1108/01443570710830593

[43] C. Y. Baldwin and K. B. Clark, "Design Rules, Vol. 1: The Power of Modularity,” MIT Press, Cambridge, 2000.

[44] A. K. W. Lau, R. C. M. Yam and E. P. Y. Tang, "Supply Chain Integration and Product Modularity: An Empirical Study of Product Performance for Selected Hong Kong Manufacturing Industries," International Journal of Operations \& Production Management, Vol. 30, No. 1, 2010, pp. 20-56. doi:10.1108/01443571011012361

[45] J. Mikkola, "Modularity, Component Sourcing, and Inter-
Firm Learning,” R\&D Management, Vol. 33, No. 4, 2003, pp. 439-454. doi:10.1111/1467-9310.00309

[46] T. J. Sturgeon, "Modular Production Networks: A New American Model of Industrial Organization,” Industrial and Corporate Change, Vol. 11, No. 3, 2002, pp. 451496. doi:10.1093/icc/11.3.451

[47] M. Schilling, "Toward a General Modular Systems Theory and Its Application to Interfirm Product Modularity," Academy of Management Review, Vol. 25, No. 2, 2000, pp. 312-334.

[48] B. Blanchard, "Systems Engineering and Management," John Wiley \& Sons, Hoboken, 2008.

[49] B. Blanchard and W. Fabrycky, "Systems Engineering and Analysis,” Prentice Hall International, Upper Saddle River, New Jersey, 2002.

[50] A. Tidstam and J. Malmqvist, "Information Modelling for Automotive Configuration,” In: A. Dagman and R. Söderberg, Eds., Proceedings of NordDesign 2010, the 8th International NordDesign Conference, Göteborg, 25-27 August 2010, pp. 275-288.

[51] A. Haug, “A Software Systems to Support the Development and Maintenance of Complex Product Configurators," International Journal of Advanced Manufacturing Technology, Vol. 49, No. 1-4, 2010, pp. 393-406. doi:10.1007/s00170-009-2396-X

[52] H. Kropsu-Vehkapera, H. Haapasalo, J. Harkonen and R. Silvola, "Product Data Management Practices in High Tech Companies,” Industrial Management \& Data Systems, Vol. 109, No. 6, 2009, pp. 758-774. doi:10.1108/02635570910968027

[53] S. Zhang, W. Shen and H. Ghenniwa, "A Review of Internet-Based Product Information Sharing and Visualization," Computers in Industry, Vol. 54, No. 1, 2004, pp. 1-15. doi:10.1016/j.compind.2003.09.002

[54] Q. Shu and Ch. Wang, "Information Modeling for Product Lifecycle Management,” In: P. Bernus and M. Fox, Eds., Knowledge Sharing in the Integrated Enterprise: Interoperability Strategies for the Enterprise Architect (IFIP International Federation for Information Processing), Springer, New York, 2005, pp. 409-416.

[55] D. Svensson and J. Malmqvist, "Strategies for Product Structure Management in Manufacturing Firms,” Journal of Computing and Information Science in Engineering, Vol. 2, No. 1, 2002, pp. 50-58. doi:10.1115/1.1471356

[56] M. M. Andreasen, C. T. Hansen and N. H. Mortensen, "The Structuring of Products and Product Programmes," Proceedings of the 2nd WDK Workshop on Product Structuring, Delft, 3-4 June 1996, pp. 15-43.

[57] V. K. Janardanan, M. Adithan and P. Radhakrishnan, "Collaborative Product Structure Management for Assembly Modelling," Computers in Industry, Vol. 59, No. 8, 2008, pp. 820-832. doi:10.1016/j.compind.2008.06.005

[58] C. Forza and F. Salvador, "Managing for Variety in the Order Acquisition and Fulfillment Process: The Contribution of Product Configuration Systems," International Journal of Production Economics, Vol. 76, No. 1, 2002, pp. 87-98. doi:10.1016/S0925-5273(01)00157-8 
[59] K. A. Jørgensen, "Product Modeling on Multiple Abstraction Levels,” In: T. Blecker and G. Friedrich, Eds., Mass Customization: Challenges and Solutions, Springer, New York, 2006, pp. 63-84.

[60] I. Crnkovic, U. Asklund and A. Persson Dahlqvist, "Implementing and Integrating Product Data Management and Software Configuration,” Artech House, Boston, 2003.

[61] A. Haug, L. Hvam and N. H. Mortensen, "A Layout Technique for Class Diagrams to Be Used in Product Configuration Projects,” Computers in Industry, Vol. 61,
No. 5, 2010, pp. 409-418.

doi:10.1016/j.compind.2009.10.002

[62] F. Colace, M. De Santo and P. Napoletano, "Product Configurator: An Ontological Approach,” Ninth International Conference on Intelligent Systems Design and Applications, Pisa, 30 November - 2 December, 2009, pp. 908-912.

[63] EU Commission, “SME Definition,” 8 March 2009. http://ec.europa.eu/enterprise/enterprise_policy/sme_defi nition/index_en.htm. 


\section{Appendix A}

Examples of interviewee comments relating to fuzzy offering.

Company

"Customer billing is demanding since the delivered configuration can be wrongly constructed due the lack of general product definitions."

A "It is not clear which parts we can configure, what are the options and especially which parts must be fixed."

"I believe that better configurability in our products would increase the quality of our deliverables, rationalise operational activities due to improved configuration repeatability and product variability. Consequently, we can offer more services with less effort."

"Product variants enable hundreds of thousands different configurations making product data management challenging since each variant structure is managed separately and final configuration means combining these variant structures. This leads to problems at the point of sales - sales personnel are not able to manage all information relating to vast product portfolio."

"Too wide product portfolio leads to overly simplified configuration processes and sales tend to copy previous solutions. This is later realised as incorrect customer orders, incorrect product combinations etc."

"Is it wise to provide millions of different combinations when the actual deliveries to customers are usually within 20 basic combinations?”

C "Managers should understand that if a company provides 5 million diverse software configurations, they should also be able to test all the available configurations before selling-which is impossible. Due to that, if a certain system is sold for the first time to a customer, for sure there is a problem - the combination is wrong, the functionality sold does not exist, etc."

"Sometimes issues are described with one sentence in a contract and the customer can understand the content differently than the

D sales personnel has meant."

"There are also some problems in managing sold items - if the content is not properly defined."

$\mathrm{E} \quad$ "The final specification of a deliverable is not clear enough during sales process, potentially resulting in, e.g. incorrect cost calculations and wrong pricing.”

F In the case F, the experiences of configurability do not exist since the company is in a planning phase and they will include configurability in their product in the near future.

\section{Appendix B}

Table 1. Current state analysis on product structure and configuration.

\begin{tabular}{|c|c|}
\hline Company & Researchers' summary on current status \\
\hline A & $\begin{array}{l}\text { Systematic configuration process and configuration management is at its initial stages. In fact, product structuring has not been } \\
\text { considered in a systematic manner at the company level. The company has recognised a need to come up with a general product } \\
\text { structure in order to efficiently manage product configuration. Development of product structure has been started from scratch. }\end{array}$ \\
\hline B & $\begin{array}{l}\text { Configuration process as a whole can be considered as being managed. General product structure is defined including all product } \\
\text { types (HW, SW, service, document). Their current product structure also contains constraints and product configuration rules. } \\
\text { Existing product structure is, however, experienced to be overly complex, and managing a wide product range as laborious. Product } \\
\text { configuration is a bundle of sales items (single product variants) which all are managed individually resulting in a vast number of } \\
\text { products to be managed. Operational personnel are unable to master a high amount of diverging information. Also, solutions to } \\
\text { product data management are considered to be too demanding. An additional challenge is faced every time when company mergers } \\
\text { take place. This is due diversities in product structures and management systems. }\end{array}$ \\
\hline $\mathrm{C}$ & $\begin{array}{l}\text { Configuration process is not systematic. Practices for structuring a product depend on individual ways of working. Product line } \\
\text { specific product structures exist only in some product lines but is not systematically utilised throughout the organisation. Adequate } \\
\text { tools do not exist, ones that would contain information on all configuration possibilities. This creates product configuration challenges } \\
\text { for sales. }\end{array}$ \\
\hline $\mathrm{D}$ & $\begin{array}{l}\text { Configuration process and configuration management is not systematic. The company has not documented product structure that } \\
\text { would describe its products. The offering is defined but the product contents are neither systematically defined nor standardised. } \\
\text { Consequently, the actual deliveries can vary. Due to the deficiency of standardised product contents also product configuration } \\
\text { management and especially the later re-configuration becomes challenging. }\end{array}$ \\
\hline $\mathrm{E}$ & $\begin{array}{l}\text { Configuration process is repetitive in nature and utilises parameterisation. Configuration is conducted at multiple product levels. } \\
\text { General product structure is not yet deliberate. The company's main product is relatively new, and the product structure is not } \\
\text { considered as fully developed and permanent, resulting in inadequate support for business processes. The service part of the product } \\
\text { has neither been systematically defined, nor managed. The product structure includes only modelling the physical product. }\end{array}$ \\
\hline $\mathrm{F}$ & $\begin{array}{l}\text { The company's product structure is relatively stable. However, the product structure is not adequately general but separately defined } \\
\text { for each variant. Variants (e.g. different colour) are managed as separate products, dramatically increasing the number of products and } \\
\text { making product data management challenging. Replacing the current product structure with a more general one is seen challenging. } \\
\text { In practice, current products are not configurable but consist of variants. The company strives for customer based configuration } \\
\text { (re-configuration) of its products in the future. However, the optimal way of doing this is unclear. }\end{array}$ \\
\hline
\end{tabular}


Table 2. Major requirements for product structure development.

\begin{tabular}{|c|c|}
\hline Company & Major requirements for product structure \\
\hline A & $\begin{array}{l}\text { The product structure to be developed has to support product configuration realised by parameters. } \\
\text { Generating clear rules for product configuration are required to support clarifying product offering throughout the company. This } \\
\text { aims to standardise product compositions and systematise product pricing. }\end{array}$ \\
\hline B & $\begin{array}{l}\text { Product structure was originally created to support hardware products. Current product range is, however, a mixture of hardware, } \\
\text { software, service, and documents. The future product structure should somehow respond to these needs without ruining the existing } \\
\text { business. One major need is to develop the product structure to better support software product and their management. }\end{array}$ \\
\hline $\mathrm{C}$ & $\begin{array}{l}\text { Product structure should cover all the product lines and the model should follow a similar logic. } \\
\text { The current partially utilised product structures are only technical specifications of individual product options. The final offering is, } \\
\text { however, a combination of these options and the product structure does currently not define the final product. There are no existing } \\
\text { rules or restrictions for combining these product options. Future product structure must contain defined rules and restrictions. }\end{array}$ \\
\hline $\mathrm{D}$ & $\begin{array}{l}\text { The company requires the future product structure to formalise the offering with a general product structure and create exact rules } \\
\text { for product configurations. } \\
\text { Also, the offered service should be defined in order to be able deliver standard content. } \\
\text { The rules for configuring a product should be made explicit. }\end{array}$ \\
\hline $\mathrm{E}$ & $\begin{array}{l}\text { The company needs to develop a general product structure, and especially consider improving the realisation of modularisation. } \\
\text { The lack of service product modelling needs to be tackled in order to better support operational processes. }\end{array}$ \\
\hline $\mathrm{F}$ & $\begin{array}{l}\text { The company needs to develop general product structure. To develop their current product structure to respond to new business } \\
\text { needs: re-configuration. These two requirements together necessitate developing a new product structure and a set the rules for } \\
\text { configurations. }\end{array}$ \\
\hline
\end{tabular}

